\title{
Assessment of chronic pain in children: Current status and emerging topics
}

\author{
Tonya Mizell Palermo PhD
}

TM Palermo. Assessment of chronic pain in children: Current status and emerging topics. Pain Res Manage 2009;14(1):21-26.

The present paper reviews the current status of research on assessment of chronic pain in children and adolescents, primarily in the context of treatment outcome research. Two specific primary aims are addressed. First, the degree of attention devoted to several major domains of chronic pain assessment (pain, physical functioning, role functioning, sleep and emotional functioning) is summarized, highlighting areas where further instrument development and validation are needed. Second, sensitivity of instruments within these domains is presented using data from clinical trials of psychological therapies aimed at treatment of chronic pain in children and adolescents. Findings demonstrate that although there has been recent progress in developing and validating a range of measures of pain-related outcomes, as of yet, very few clinical trials have included any outcomes other than pain intensity. Moreover, in randomized controlled trials where physical, role or emotional functioning outcomes have been included, there have been limited positive findings. The present paper lists some challenges and future directions in assessment of physical and role functioning, including highlighting emerging methodologies for assessment of physical activity and function in children with chronic pain. Clinical implications of integrating assessment tools into clinical practice are discussed. In conclusion, progress in developing and validating specific tools to assess important outcome domains in chronic pain has been realized. Opportunities exist for further measurement validation in most domains, and further theory-driven treatment research to match goals of the treatment with specific interventions and outcomes.

Key Words: Assessment; Children; Chronic pain; Physical functioning; Treatment outcomes

\section{Évaluation de la douleur chronique chez l'enfant : Situation actuelle et nouvelles tendances}

Le présent article fait le point sur la situation actuelle de la recherche en matière d'évaluation de la douleur chronique chez les enfants et les adolescents, principalement dans le contexte de la mesure des résultats des traitements. On y aborde deux grands axes spécifiques. Premièrement, on résume le degré d'attention consacré à plusieurs importantes variables de l'évaluation de la douleur chronique (douleur, fonctionnement physique, fonctionnement social, sommeil et fonctionnement émotionnel), tout en mettant en relief celles pour lesquelles il faudrait perfectionner et valider les instruments de mesure. Deuxièmement, on présente la sensibilité des instruments utilisés pour mesurer ces variables, à partir de données tirées d'essais cliniques sur les psychothérapies visant à traiter la douleur chronique chez les enfants et les adolescents. Selon les conclusions, bien que des progrès aient été réalisés récemment aux chapitres de la mise au point et de la validation d'une gamme d'outils de mesure des résultats, pour l'instant encore, très peu d'essais cliniques ont évalué d'autres paramètres que l'intensité de la douleur. De plus, lors des essais randomisés et contrôlés qui ont porté sur les paramètres de fonctionnement physique, social ou émotionnel, on a enregistré peu de résultats positifs. Le présent article explique quelques-uns des défis et les orientations futures de l'évaluation du fonctionnement physique et social, et met en relief les méthodologies émergentes pour l'évaluation de l'activité et du fonctionnement physiques chez les enfants souffrant de douleur chronique. Il aborde les répercussions cliniques de l'intégration des outils d'évaluation à la pratique. Pour conclure, des progrès ont été accomplis dans la mise au point et la validation d'outils spécifiques pour évaluer les principales composantes de la douleur chronique. Il y a toutefois lieu de travailler à une meilleure validation dans la majeure partie de ces domaines, et d'approfondir la recherche théorique afin que les objectifs thérapeutiques concordent avec les interventions et résultats spécifiques.

important to develop effective treatments and measure response to these interventions.

Recently, recommendations have been made by experts convening at a consensus conference, the Pediatric Initiative on Methods, Measurement, and Pain Assessment in Clinical Trials (Ped-IMMPACT), concerning outcome domains (and measures) that are important to assess in clinical trials with children and adolescents who have acute as well as chronic or recurrent pain (5). Such work toward standardization of outcome domains and measures in pediatric pain randomized controlled trials (RCTs) may encourage further intervention trials, simplify and strengthen interpretation and aggregation of results, and help clinicians make treatment decisions (5). Eight domains were identified for chronic pain assessment, including pain intensity, physical functioning, symptoms and domains of normal daily life. Although many children with pain conditions cope well, a subgroup of children and adoles cents with chronic pain will have poor school attendance, reduced participation in athletic and social activities, and sleep disturbances. Children may also report lower quality of life and higher levels of distress, anxiety and depression (2,3). This problem is amplified by the fact that children with recurrent or chronic pain may continue into adulthood with chronic pain, other physical complaints and psychiatric symptoms (4). Attention to the assessment of chronic pain in children is

Anesthesiology $\mathcal{E}$ Peri-Operative Medicine, Oregon Health $\mathcal{E}$ Science University, Portland, Oregon, USA

Correspondence: Dr Tonya Mizell Palermo, Anesthesiology $\mathcal{G}$ Peri-Operative Medicine, Department of Anesthesiology, Oregon Health $\mathcal{F}$ Science

University, UHN-2, 3181 SW Sam Jackson Park Road, Portland, Oregon 97239, USA. Telephone 503-494-0848, fax 503-494-3092,

e-mail palermot@ohsu.edu 
adverse events, global satisfaction with treatment, emotional functioning, role functioning, sleep and economic factors. Because the identification of these core domains represents important progress in the field, it was considered pertinent to the goals of the present paper to focus on the degree of attention devoted to these domains in the context of pediatric pain treatment outcome research. However, because there has been insufficient development of measures in three domains (symptoms and adverse events, global satisfaction with treatment, and economic factors), such that the Ped-IMMPACT group did not recommend any specific available measures within these domains (5), a decision was made to exclude these areas from the present review.

Therefore, the two primary aims of the present review are to summarize the degree of attention devoted in treatment intervention studies to several major domains of chronic pain assessment: pain, physical functioning, role functioning, sleep and emotional functioning, highlighting areas where further instrument development and validation are needed; and review data concerning the sensitivity of instruments within these domains using outcome data from clinical trials of psychological therapies for treatment of chronic pain in children and adolescents. The two secondary aims are to discuss emerging topics in assessment of chronic pain in children and clinical applications of evidence-based assessment. The present paper is not meant to serve as an exhaustive review of available assessment tools for children with chronic pain, because other, more extensive reviews are available (6).

\section{ASSESSMENT OF PAIN}

As opposed to assessment of acute pain, there are multiple dimensions of pain that may be important to assess in children and adolescents with chronic pain. In addition to the intensity of pain, other characteristics such as pain duration, frequency and location are relevant. Many tools are available to assess children's self-reported pain intensity and there are two recent reviews on this topic. Stinson et al (7) completed a systematic review of self-report pain intensity measures for children aged three to 18 years. This review was commissioned by the PedIMMPACT group to help guide decisions about pain measures that may be recommended for use in clinical trials in children and adolescents. A separate task force commissioned by the Society of Pediatric Psychology completed reviews of evidencebased assessment in multiple topic areas, including pediatric pain assessment (8).

In general, both reviews considered available psychometric data for self-reported pain measures and made global recommendations about the suitability for use in clinical trials and/or the strength of the evidence base for each measure. Stinson et al (7) presented recommendations for measuring self-reported pain intensity in clinical trials by developmental status and type of pain. Relevant to chronic pain assessment, the Faces Pain Scale - Revised (9) was recommended for children between four and 12 years of age. A $100 \mathrm{~mm}$ visual analogue scale was recommended for children older than eight years of age. Cohen et al (8) also reviewed multidimensional pain scales, finding the Varni/Thompson Pediatric Pain Questionnaire (10) to have a strong evidence base.

Pain diaries are often used in the assessment of chronic pain to obtain estimates of the frequency, intensity and duration of pain over time. Diaries offer several potential advantages over retrospective self-report pain assessment. In particular, diaries may improve accuracy of children's pain reports because they are completed 'in the moment', reducing reporting biases found on retrospective measures. Electronic diaries are now widely used and offer additional benefits in capturing children's realtime pain responses. In the review by Cohen et al (8), only one paper pain diary had an available strong evidence base. Emerging work on electronic diaries will provide increased opportunities for assessment of chronic pain symptoms (see Stinson, pages 59-64 in the present issue of Pain Research $\mathcal{E}$ Management), which is relevant for treatment studies using diaries to gather pain intensity data.

\section{Sensitivity of pain measures}

In the psychological clinical trial literature, pain intensity is the single most frequently reported treatment outcome (11). Additional pain indices that integrate pain intensity and frequency data from diaries have often been reported in clinical trials of children with headaches (eg, headache index). The most frequently used assessment tools are the 11-point numerical rating scale and visual analogue scale. In their systematic review of psychological therapies for chronic pediatric pain, Eccleston et al (11) reported significant reduction in pain intensity $(\mathrm{OR}=9.62)$ in youth receiving psychological therapy versus youth who did not. These computations were based on a clinically significant reduction of $50 \%$ or greater in pain intensity ratings. Future research is needed on the psychometric properties of the 11-point numerical rating scale and pain indices derived from diaries, which are commonly employed in clinical trials.

\section{ASSESSMENT OF PHYSICAL AND ROLE FUNCTIONING}

The domains of physical and role functioning are considered together here due to the lack of distinction of these concepts in many of the available measures. Enhancing children's functioning is often the primary treatment goal for youth with chronic pain. Children and adolescents with chronic pain demonstrate functional impairment on many self-report measures in such areas as school functioning, social and relationship functioning, physical activity and family responsibilities $(12,13)$. However, the relationship between pain and functional impairment is not linear, and changes in children's pain symptoms are not necessarily associated with changes in functional impairment (3).

Several terms have been used interchangeably to refer to a child's ability to perform age-appropriate activities and maintain roles in their daily life, including functional disability, activity limitations, physical functioning and role functioning. In the present paper, the term 'physical and role functioning' will be used to refer to this multidimensional domain concerned with children's participation in vigorous physical activities (eg, sports and running), recreational and social activities (eg, hanging out with friends), and important roles (eg, school and chores). Several measures are currently available to assess these constructs and there are two relevant review articles $(6,14)$ that provide details on available measures. The first review is of measures of functional impairment and healthrelated quality of life for the Society of Pediatric Psychology 
task force series on evidence-based assessment (14). Although not exclusive to measures used for pain assessment, the review includes measures that have commonly been used in youth with chronic pain. The second review is specifically of measures that assess pain impact in children (6). It provides detailed psychometric information on measures of pain impact, including physical and role functioning. In general, there are several well-validated measures of physical and role functioning, such as the Functional Disability Inventory (FDI) (12), that can be used in youth with chronic pain.

\section{Use of multidimensional measures}

Several multidimensional measures of pain impact have been developed in recent years. The Bath Adolescent Pain Questionnaire assesses multiple domains of impairment (eg, social functioning, physical functioning and depression) in adolescents and has strong reliability and validity in preliminary reports (15). Another new measure, the Pain Experience Questionnaire, assesses multiple domains of pain and its psychosocial impact on children (16). In addition, also relevant to multidimensional assessment are generic health-related quality of life measures such as the Pediatric Quality of Life Inventory (PedsQL) (17). Such measures have been used in samples of children with chronic pain and offer the advantage of extensive validation and comparison data among children with other chronic health conditions and healthy children.

\section{Sensitivity of physical and role functioning measures}

Very few RCTs of psychological treatments have measured change in children's physical or role functioning from pre- to post-treatment. In five recent RCTs, functional disability or quality of life outcomes were used. Robins et al (18) found no changes on the FDI with family cognitive behavioural therapy (CBT) in children with recurrent abdominal pain. In a trial in youth with juvenile fibromyalgia, Kashikar-Zuck et al (19) found a significant time effect for reduction in functional disability on the FDI but no group effect was found. Headache-related disability was assessed as an outcome in two RCTs of children with headache using the Pediatric Migraine Disability Assessment Scale. In both trials $(20,21)$, a time effect only was found for both treatment and control groups to decrease headache-related disability over time. One recent randomized Web-based CBT trial (22) did not show changes in quality of life outcomes on the PedsQL in youth with recurrent headache or abdominal pain.

In three uncontrolled trials using the FDI (23-25), changes in physical functioning have been described. CBT in juvenile fibromyalgia improved functional ability from pre- to posttreatment (23). Similarly, one inpatient multicomponent intervention that included CBT improved pain-related disability among adolescents with longstanding chronic pain (24). A CBT intervention focused on acceptance and exposure improved functional ability in adolescents with idiopathic pain (25). Thus, while psychological interventions are largely found to be effective in reducing pain intensity (11), a significant gap remains in our knowledge of the effects of psychological interventions on physical and role functioning, especially in RCTs.

\section{Conclusions and discussion}

There is little evidence from RCTs that physical or role functioning is effectively changed by psychological treatments.
One possible explanation for the lack of robust findings is that measures used to assess physical and role functioning may be limited in their sensitivity in demonstrating short-term changes. Previous studies have primarily examined physical or role functioning via self-report measures, which are subject to response shift and reporter bias, and are a particular challenge for pediatric research on functional outcomes such as quality of life (26). Response shift occurs when subjects change their internal standard for determining their level of functioning. Thus, changes in subjective reports from pre- to post-treatment may reflect internal, subjective changes in how a subject views his or her health, rather than an observable change in functioning (26). Available measures of physical functioning share several weaknesses, including lack of cutoff scores or any indicator of the clinical significance of specific levels of impairment, and little data on predictive validity. Beyond basic psychometric data on reliability and validity of the measures, there has been limited use of other validation approaches such as factor analysis to provide more information regarding the constructs being measured. The exception to this is work done on generic health-related quality of life measures, such as the PedsQL, in which factorial structure has been reported. However, analyses in clinical trials using the PedsQL have been done on the first-order scale (total score) rather than for subscales concerning physical or role functioning. Although more reliable, the first-order scale may be less sensitive to changes in clinical status, limiting the detection of meaningful changes in physical or role functioning.

\section{Example of validation data from a measure of physical functioning}

As an illustration of how factor analysis can extend information about instruments designed to measure physical functioning, recent work on the Child Activity Limitations Interview (CALI) is briefly described. The CALI was originally designed as an interview measure of children's pain-related activity limitations (27), and was also adapted as a written selfreport measure. The measure asks children and parents to report on pain-related limitations in 21 activities in a variety of areas over the previous four weeks. A factor analysis was conducted to document the CALI's factor structure using data from 155 treatment-seeking children and adolescents with chronic pain (28). Factor analysis was approached from the assumption that physical functioning, as measured by the CALI, would not be unidimensional. Previous research has documented different patterns between child psychological and family correlates and items assessing functional impairment.

Results of the exploratory factor analysis of the CALI-21 data yielded two factors representing limitation in active and routine activities (28). Endorsement of limitations on the active factor (eg, gym, sports and running) indicates children report difficulty in vigorous physical activities. In contrast, limitations on the routine factor (eg, schoolwork, reading and eating regular meals) indicate children have difficulty with activities of daily living and learning tasks. Parent and child reports yielded similar patterns of loadings on the Active and Routine factors. Parent and child total CALI scores correlated with measures of pain intensity; however, different patterns of correlations emerged between age, pain intensity, depressive 
symptoms, and the active and routine factors across parent and child reports. Additional measurement work such as factor analysis may allow for increased precision and sensitivity to capturing changes in the clinical status of children's physical functioning in clinical trials.

\section{ASSESSMENT OF EMOTIONAL FUNCTIONING}

Children's emotional functioning has been considered both as a predictor or moderator of treatment response as well as a salient outcome domain in chronic pain treatment. Given that children with chronic pain often demonstrate increased levels of anxiety and depressive symptoms, it is important to understand how treatment may lead to changes in emotional functioning. In general, psychological measures of anxiety and depressive symptoms have been used to provide information on emotional functioning. Less commonly, psychiatric interviews have been employed to obtain psychiatric diagnostic information. In their review of pain impact measures, Eccleston et al (6) provided psychometric information, descriptions of study populations, and usage of each instrument to assess emotional functioning. They reported that the two most commonly used measures of emotional functioning in children with chronic pain were the Child Behavior Checklist (29) and the Children's Depression Inventory (30). As multidimensional measures are being developed to assess pain-related impact, it is important to consider how emotional functioning subscales perform in comparison with commonly used measures, particularly in sensitivity to change and predictive validity.

\section{Sensitivity of emotional functioning measures}

In the psychological clinical trial literature, few RCTs have included children's emotional functioning as an outcome. In one RCT of CBT in juvenile fibromyalgia, Kashikar-Zuck et al (19) found a significant time effect for reduction in depressive symptoms on the Child Depression Inventory at post-treatment; however, there were no significant group differences. In an uncontrolled study of inpatient rehabilitation, reduction in anxiety symptoms was found on the Spence Child Anxiety Scale post-treatment and at follow-up (24). Clearly, this remains an area in which further work is needed to better understand whether measures of emotional functioning are sensitive to changes produced by treatment.

\section{ASSESSMENT OF SLEEP}

On subjective self-report, the prevalence of sleep difficulties in children and adolescents with chronic pain is high, representing a common complaint (31). Difficulties falling asleep, frequent arousals, night and early morning awakening, and poor sleep quality have been reported by children and adolescents with a number of specific chronic pain conditions.

Sleep is a multidimensional outcome variable comprised of specific components such as sleep duration, sleep problems (eg, insomnia) and sleep quality. Subjective survey instruments are available to assess different dimensions of sleep, such as the Children's Sleep Habits Questionnaire (32), which provides information about a range of sleep disorders. Other survey instruments are available to measure a single component of sleep such as sleep quality (eg, the Adolescent Sleep-Wake Scale) (33). In addition, sleep times can be recorded on an annotated diary and measured via objective methods such as actigraphy to obtain information about the total amount of sleep.

An actigraph is a small watch-like device, commonly worn on the wrist to record body movements during the night, that allows for unobtrusive measurement of motion over extended periods in the home environment (34). This methodology shows excellent validity compared with concomitant polysomnography, with agreement rates of $85 \%$ to $95 \%$ in most samples (35). Actigraphy has been used to monitor sleep patterns of adolescents with chronic pain (36), finding that adolescents with chronic pain had lower sleep efficiency (indicative of poor quality sleep) and more night wakings compared with healthy adolescents.

\section{Sensitivity of sleep measures}

Sleep has rarely been included as an outcome in psychological treatment studies for chronic pain. The one exception is in an uncontrolled trial of CBT for juvenile fibromyalgia. Degotardi et al (23) found that subjective perception of sleep quality was improved on the Pittsburgh Sleep Quality Index (an adult measure of sleep quality) from pre- to post-treatment. Sleep is another domain in which additional clinical trial work is needed to understand the potential impact of interventions for chronic pain. Objective assessment tools such as actigraphy provide additional opportunities for measuring sleep outcomes in clinical trials.

\section{NEW AND EMERGING TOPICS}

In this section, new methodologies for examining physical activity are described as one example of a new and emerging topic in chronic pain assessment. Because actigraphy provides a measure of movement it also allows for objective assessment of the intensity of daytime activity level. Actigraphy has been used successfully to monitor activity level in a number of adult pain populations where activity levels have been shown to be much lower than in otherwise healthy adults (37). One advantage of actigraphy technology is that it provides a record of regular daytime activity over an extended period and may capture more naturalistic aspects of daytime functioning in comparison with performance-based tasks (such as a timed walk).

In the one pediatric study conducted to date, Long et al (38) compared activity levels of adolescents with chronic pain and healthy adolescents using actigraphy and subjective measures of functioning. Activity levels were assessed over seven consecutive days with ambulatory actigraphy and two activity scores were used - mean and peak activity level achieved per $24 \mathrm{~h}$ period. Findings showed that adolescents with chronic pain had lower activity levels than healthy peers. Mean and peak activity were inversely correlated with pain frequency, intensity and depression. Peak activity was also significantly correlated with subjective activity limitations and fatigue. Activity levels assessed via actigraphy may be a useful additional measure for examining physical functioning outcomes in youth with chronic pain.

Several other objective methods have been used to evaluate physical activity or physical performance. In one uncontrolled trial of an inpatient multicomponent rehabilitation program (24), performance-based measures of physical performance, a timed $10 \mathrm{~m}$ walk, and the number of sit-to-stand movements completed in $1 \mathrm{~min}$, improved from pre- to post-treatment, 
along with subjective perception of functional disability. Both actigraphy and performance-based measures offer additional information concerning change in children's physical activity levels, and may provide useful data in multimodal assessment of children's physical functioning.

\section{CLINICAL ASSESSMENT OF THE PEDIATRIC PATIENT}

How do the developments in assessment apply to clinical evaluation of an individual child with chronic pain and his or her family? The following section focuses on clinical evaluation of chronic pain in the context of multidisciplinary treatment.

Many multidisciplinary treatment programs have developed intake questionnaires that include assessment tools in an effort to obtain standardized information on patients. Along with pain history information, intake packets may include standardized psychological assessment tools such as depression rating scales or measures of functional disability. Ideally, the clinical interview with the parent(s) and patient supplements and extends information gathered via an intake packet, allowing clinicians to hone in on potential areas of concern. The interview alone with the parent should cover important details about the child's pain and current functioning. Asking the parent to describe a typical day starting with when the child wakes in the morning provides an opportunity to inquire about schedules and routines as well as how pain interferes with the child's normal daily activities. Interview probes can elicit the parent's response to the child's pain complaints, providing detail about positive and maladaptive patterns. The interview with the parent can also touch on their own emotional functioning including the experience of anxiety and marital stress related to dealing with the child's chronic pain.

Alone with the child, the interviewer can make observations about the child's mental status, and inquire about the child's feelings about treatments, level of distress about the pain problem, and general way of coping with pain and negative feelings. Asking the child to describe a typical day can also give information about how pain is managed, which activities are limited due to pain, and relative amount of time spent in activity versus bed rest. A general inquiry about sleep patterns and schedules kept on school days and nonschool days can give

\section{REFERENCES}

1. Perquin CW, Hazebroek-Kampschreur AA, Hunfeld JA, et al. Pain in children and adolescents: A common experience. Pain 2000;87:51-8.

2. Fichtel A, Larsson B. Psychosocial impact of headache and comorbidity with other pains among Swedish school adolescents. Headache 2002:42:766-75.

3. Palermo TM. Impact of recurrent and chronic pain on child and family daily functioning: A critical review of the literature. J Dev Behav Pediatr 2000;21:58-s69.

4. Fearon P, Hotopf M. Relation between headache in childhood and physical and psychiatric symptoms in adulthood: National birth cohort study. BMJ 2001;322:1145.

5. McGrath PJ, Walco GA, Turk DC, et al. Core outcome domains and measures for pediatric acute and chronic/recurrent pain clinical trials: PedIMMPACT recommendations. J Pain 2008;9:771-83.

6. Eccleston C, Jordan AL, Crombez G. The impact of chronic pain on adolescents: A review of previously used measures. J Pediatr Psychol 2006;31:684-97. an estimate of sleep duration. Problems falling asleep or staying asleep can give an indication of sleep quality.

Issues such as availability of measures, cost and ease of administration are critical to address in using assessment tools in the clinical setting. Documentation of outcomes via integration with electronic medical records (EMR) is a particularly relevant practical solution to address. Many EMR systems allow clinicians to build templates, which could incorporate identified outcome tools. Moreover, reassessment plans for documenting outcomes at each visit can be enhanced by EMR fields. Quality improvement science may provide avenues for testing the implementation of outcome tools in specific institutional settings.

\section{SUMMARY AND FUTURE DIRECTIONS}

Progress has been realized in defining relevant outcome domains to assess in children with chronic pain, and in developing and validating specific instruments. There are clearly areas of opportunity for measure development in domains that have received little attention to date, such as economic factors and adverse events, as well as in further validation of existing measures. As the psychological clinical trial research demonstrates, multidimensional assessment of treatment outcome is challenging. While not all trials can be expected to assess all pertinent outcome domains (and target treatment toward all areas), there are clearly large gaps in evidence available from RCTs of psychological treatments on nonpain outcomes in children. Lack of positive effects on nonpain outcomes may be due to problems with insensitive measures or with treatment content and focus. Therefore, in addition to attention to measurement, an equally important area of opportunity is in treatment research. Increased attention to conceptualizing the content and aims of psychological treatments for pediatric chronic pain is needed. Given that the relationship between pain and function is not linear, it would be erroneous to assume that changes in pain will correlate with changes in function. Theory is needed for how interventions will specifically address nonpain outcomes such as function. Investigators rising to this challenge will provide theory-driven treatment research, clearly specifying the goals and domains targeted by individual treatment techniques, and matching domains targeted by treatment to validated outcome measures.
7. Stinson JN, Kavanagh T, Yamada J, Gill N, Stevens B. Systematic review of the psychometric properties, interpretability and feasibility of self-report pain intensity measures for use in clinical trials in children and adolescents. Pain 2006;125:143-57.

8. Cohen LL, Lemanek K, Blount RL, et al. Evidence-based assessment of pediatric pain. J Pediatr Psychol 2008;33:939-55.

9. Hicks CL, von Baeyer CL, Spafford PA, van Korlaar I, Goodenough B. The Faces Pain Scale-Revised: Toward a common metric in pediatric pain measurement. Pain 2001;93:173-83.

10. Varni JW, Thompson KL, Hanson V. The Varni/Thompson Pediatric Pain Questionnaire. I. Chronic musculoskeletal pain in juvenile rheumatoid arthritis. Pain 1987;28:27-38.

11. Eccleston C, Morley S, Williams A, Yorke L, Mastroyannopoulou K. Systematic review of randomised controlled trials of psychological therapy for chronic pain in children and adolescents, with a subset meta-analysis of pain relief. Pain 2002;99:157-65.

12. Walker LS, Greene JW. The functional disability inventory: Measuring a neglected dimension of child health status. J Pediatr Psychol 1991;16:39-58. 
13. Palermo TM, Witherspoon D, Valenzuela D, Drotar DD. Development and validation of the Child Activity Limitations Interview: A measure of pain-related functional impairment in school-age children and adolescents. Pain 2004;109:461-70.

14. Palermo TM, Long AC, Lewandowski AS, Drotar D, Quittner AL, Walker LS. Evidence-based assessment of health-related quality of life and functional impairment in pediatric psychology. J Pediatr Psychol 2008;33:983-96.

15. Eccleston C, Jordan A, McCracken LM, Sleed M, Connell H, Clinch J. The Bath Adolescent Pain Questionnaire (BAPQ): Development and preliminary psychometric evaluation of an instrument to assess the impact of chronic pain on adolescents. Pain 2005;118:263-70.

16. Hermann C, Hohmeister J, Zohsel K, Tuttas M, Flor H. The impact of chronic pain in children and adolescents: Development and initial validation of a child and parent version of the Pain Experience Questionnaire. Pain 2008;135:251-61.

17. Varni JW, Seid M, Rode CA. The PedsQL: Measurement model for the pediatric quality of life inventory. Med Care 1999;37:126-39.

18. Robins PM, Smith SM, Glutting JJ, Bishop CT. A randomized controlled trial of a cognitive-behavioral family intervention for pediatric recurrent abdominal pain. J Pediatr Psychol 2005;30:397-408.

19. Kashikar-Zuck S, Swain NF, Jones BA, Graham TB. Efficacy of cognitive-behavioral intervention for juvenile primary fibromyalgia syndrome. J Rheumatol 2005;32:1594-602.

20. Abram HS, Buckloh LM, Schilling LS, Armatti Wiltrout S, Ramirez-Garncia G, Turk WR. A randomized, controlled trial of a neurological and psychoeducational group appointment model for pediatric headaches. Child Health Care 2007:36:249-65.

21. Connelly M, Rapoff MA, Thompson N, Connelly W. Headstrong: A pilot study of a CD-ROM intervention for recurrent pediatric headache. J Pediatr Psychol 2006;31:737-47.

22. Hicks TV, Leitenberg H, Barlow DH, Gorman JM, Shear MK, Woods SW. Physical, mental, and social catastrophic cognitions as prognostic factors in cognitive-behavioral and pharmacological treatments for panic disorder. J Consult Clin Psychol 2005;73:506-14.

23. Degotardi PJ, Klass ES, Rosenberg BS, Fox DG, Gallelli KA, Gottlieb BS. Development and evaluation of a cognitive-behavioral intervention for juvenile fibromyalgia. J Pediatr Psychol 2006;31:714-23.

24. Eccleston C, Malleson PN, Clinch J, Connell H, Sourbut C. Chronic pain in adolescents: Evaluation of a programme of interdisciplinary cognitive behaviour therapy. Arch Dis Child 2003;88:881-5.

25. Wicksell RK, Melin L, Olsson GL. Exposure and acceptance in the rehabilitation of adolescents with idiopathic chronic pain - A pilot study. Eur J Pain 2007;11:267.

26. Brossart DF, Clay DL, Willson VL. Methodological and statistical considerations for threats to internal validity in pediatric outcome data: Response shift in self-report outcomes. J Pediatr Psychol 2002;27:97-107.

27. Palermo TM, Witherspoon D, Valenzuela D, Drotar D. Development and validation of the Child Activity Limitations Interview: A measure of pain-related functional impairment in school-age children and adolescents. Pain 2004;109:461-70.

28. Palermo TM, Lewandowski AS, Long AC, Burant CJ. Validation of a self-report questionnaire version of the Child Activity Limitations Interview (CALI): The CALI-21. Pain 2008;139:644-52.

29. Achenbach TM, Edelbrock CS. Behavioral problems and competencies reported by parents of normal and disturbed children aged four through sixteen. Monogr Soc Res Child Dev 1981;46:1-82.

30. Kovacs M. The Children's Depression Inventory (CDI). Psychopharmacol Bull 1985;21:995-8.

31. Roth-Isigkeit A, Thyen U, Stoven H, Schwarzenberger J, Schmucker P. Pain among children and adolescents: Restrictions in daily living and triggering factors. Pediatrics 2005;115:e152-62.

32. Owens JA, Spirito A, McGuinn M. The Children's Sleep Habits Questionnaire (CSHQ): Psychometric properties of a survey instrument for school-aged children. Sleep 2000;23:1043-51.

33. LeBourgeois MK, Giannotti F, Cortesi F, Wolfson AR, Harsh J. The relationship between reported sleep quality and sleep hygiene in Italian and American adolescents. Pediatrics 2005;115(1 Suppl):257-65.

34. Ancoli-Israel S, Cole R, Alessi C, Chambers M, Moorcroft W, Pollak CP. The role of actigraphy in the study of sleep and circadian rhythms. Sleep 2003;26:342-92.

35. Sadeh A, Hauri PJ, Kripke DF, Lavie P. The role of actigraphy in the evaluation of sleep disorders. Sleep 1995;18:288-302.

36. Palermo TM, Toliver-Sokol M, Fonareva I, Koh JL. Objective and subjective assessment of sleep in adolescents with chronic pain compared to healthy adolescents. Clin J Pain 2007;23:812-20.

37. Spenkelink CD, Hutten MM, Hermens HJ, Greitemann BO. Assessment of activities of daily living with an ambulatory monitoring system: A comparative study in patients with chronic low back pain and nonsymptomatic controls. Clin Rehabil 2002;16:16-26.

38. Long AC, Palermo TM, Manees AM. Brief report: Using actigraphy to compare physical activity levels in adolescents with chronic pain and healthy adolescents. J Pediatr Psychol 2008;33:660-5. 


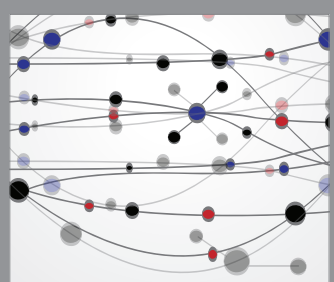

The Scientific World Journal
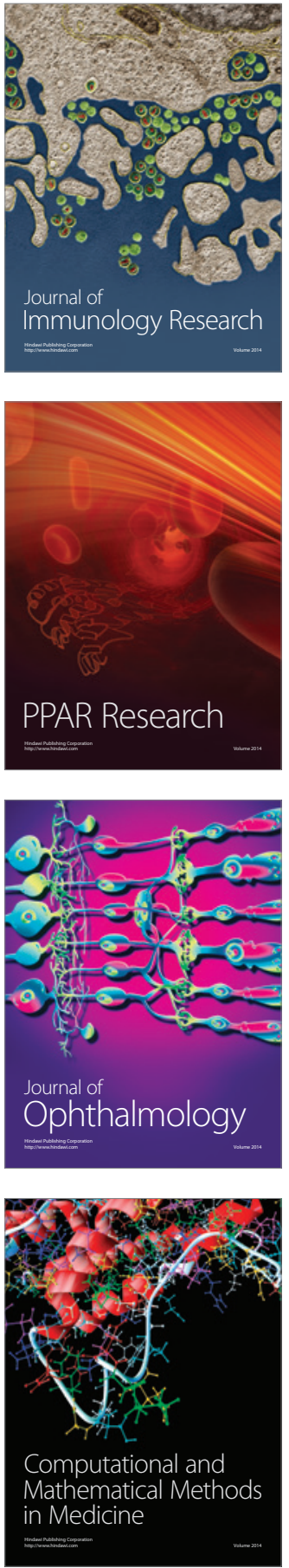

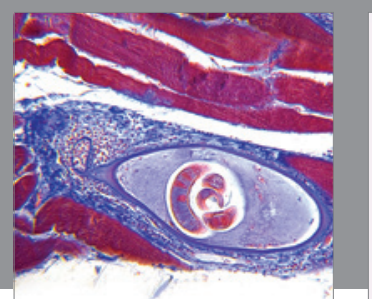

Gastroenterology Research and Practice

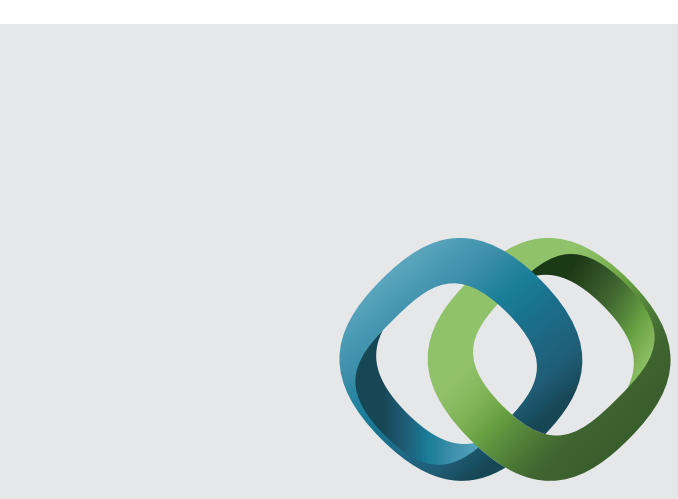

\section{Hindawi}

Submit your manuscripts at

http://www.hindawi.com
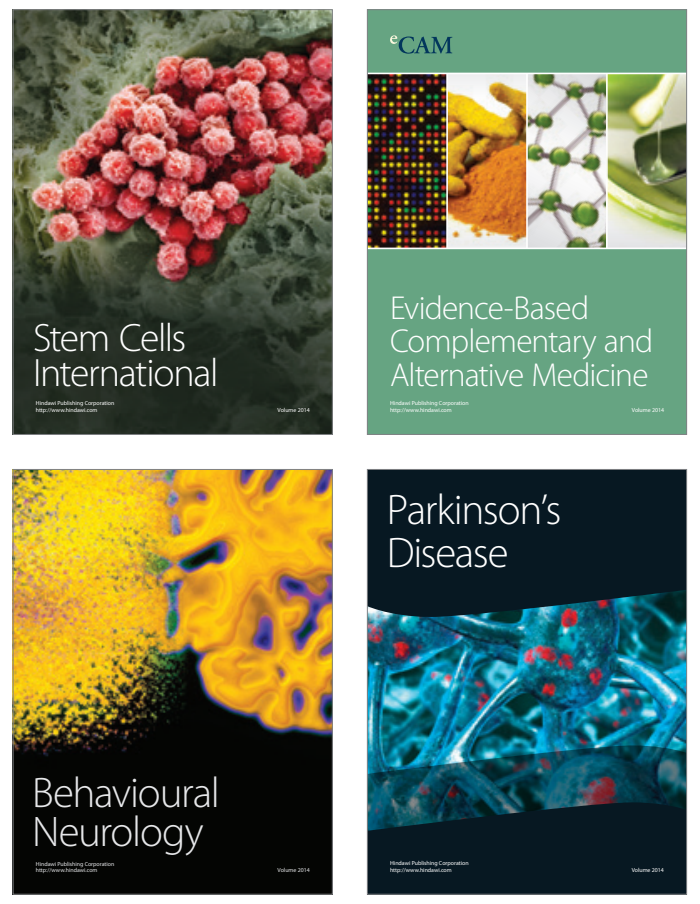
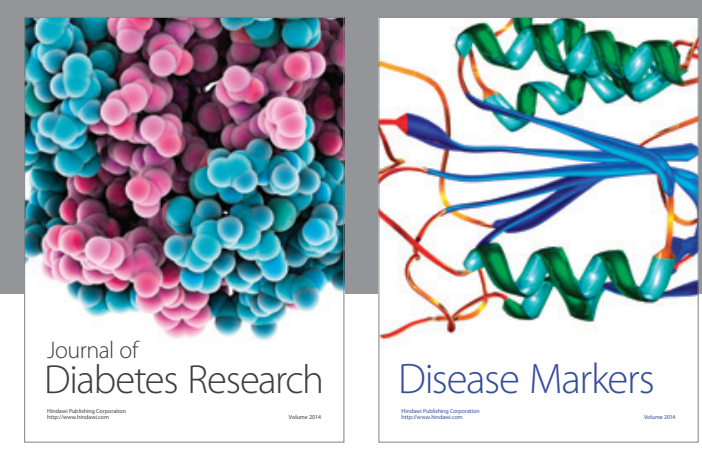

Disease Markers
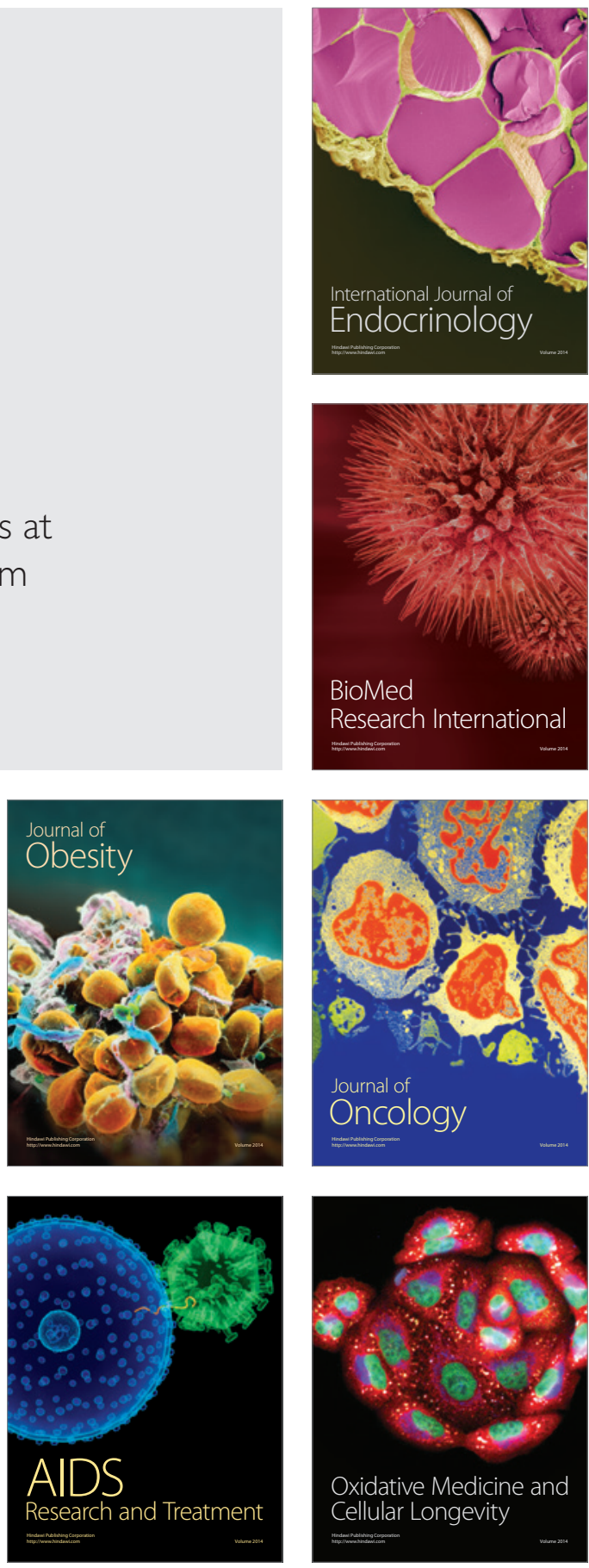